\title{
Height supersedes weight: Height-diameter indexing keeps you ahead of the game
}

\author{
Martin Czerny, MD, MBA
}

\author{
From the University Heart Center Freiburg-Bad Krozingen, Freiburg, Germany. \\ Disclosures: Author has nothing to disclose with regard to commercial support. \\ Received for publication Nov 14, 2017; accepted for publication Nov 16, 2017; available ahead of print Jan 13, \\ 2018. \\ Address for reprints: Martin Czerny, MD, MBA, Albert Ludwigs University Freiburg, Faculty of Medicine, Uni- \\ versity Heart Center Freiburg-Bad Krozingen, Südring 15, Freiburg 79189, Germany (E-mail: martin.czerny @ \\ universitaets-herzzentrum.de). \\ J Thorac Cardiovasc Surg 2018;155:1925 \\ $0022-5223 / \$ 36.00$ \\ Copyright (C) 2017 by The American Association for Thoracic Surgery \\ https://doi.org/10.1016/j.jtcvs.2017.11.053
}

Recommending elective surgery for proximal thoracic aortic pathology at a given diameter remains a dynamic process, periodically shifting a few millimeters up or down the scale along with the current literature and the current perception. This process is affected by several components. One component is formed by a least common denominator, mostly being recommendations being formulated in guidelines. Another is personal experience, mostly triggered either by adverse outcome in early surgery (should have observed longer) or by adverse aortic events when having observed too long (should have intervened earlier). Furthermore, innovative scientific work affects our decision making, defining such additional surrogates of need for treatment as aortic valve cuspidity, aortic root and ascending aorta morphology, ascending aortic length, and arch variants, as well as such subjective parameters as the ratio of ascending to descending aortic diameter. ${ }^{1-3}$ Thus, the longer one deals with the topic, the more confused one gets. The decision is confounded even more when reflecting that the texture of the aortic wall in a $5.3-\mathrm{cm}$ ascending aneurysm might be by far more fragile than that in a $7.5-\mathrm{cm}$ aneurysm in terms of tactile feedback in the operating room.

All these confounding details emphasize the importance of the key message of the study in this issue of the Journal by Zafar and colleagues. ${ }^{1}$ This report elegantly harmonizes all aspects of the disease under a single umbrella and delivers a simple message: Patients with ascending aortic aneurysms do develop complications, and if you index height to aortic diameter, you remain ahead of the game.

This report adds clarity, and it is highly likely that this work will have effect on the next version of clinical practice

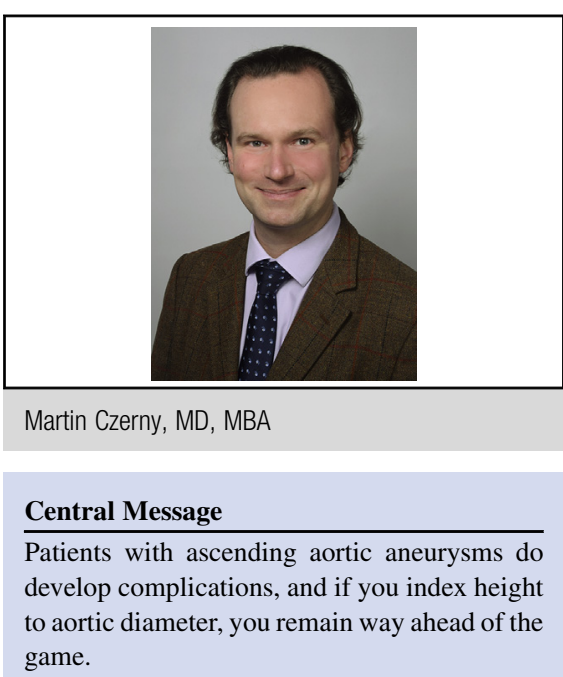

See Article page 1938.

guidelines, in which a very guarded approach is currently promoted. We should be very clear that a more liberal indication for any kind of thoracic aortic procedure must be justified by excellent perioperative results; after all, the treatment decision weighs the remaining risk of the natural course of the disease against the remaining risk of treatment. Because the results of perioperative outcome after elective proximal thoracic aortic surgery are outstanding in many settings, however, the time is right for lowering the threshold for indicating treatment by applying the suggested approach.

\section{References}

1. Zafar MA, Li Y, Rizzo JA, Charilaou P, Saeyeldin A, Velasquez CA, et al. Height alone (rather than body surface area) suffices for risk estimation in ascending aortic aneurysm. J Thorac Cardiovasc Surg. 2018;155:1938-50.

2. Krüger T, Oikonomou A, Schibilsky D, Lescan M, Bregel K, Vöhringer L, et al. Aortic elongation and the risk for dissection: the Tübingen Aortic Pathoanatomy (TAIPAN) project. Eur J Cardiothorac Surg. 2017;51:1119-26.

3. Dumfarth J, Chou AS, Ziganshin BA, Bhandari R, Peterss S, Tranquilli M, et al. Atypical aortic branch variants: a novel marker for thoracic aortic disease. $J$ Thorac Cardiovasc Surg. 2015;149:1586-92. 